\title{
Passive exoskeletons for assisting limb movement
}

\author{
Tariq Rahman, PhD; ${ }^{*}$ Whitney Sample; ${ }^{1}$ Shanmuga Jayakumar, MD; ${ }^{2}$ Marilyn Marnie King; ${ }^{3}$ Jin Yong Wee; \\ Rahamim Seliktar, PhD; ${ }^{4}$ Michael Alexander, MD; ${ }^{5}$ Mena Scavina, DO; ${ }^{6}$ Alisa Clark ${ }^{6}$ \\ Departments of ${ }^{1}$ Biomedical Research, ${ }^{2}$ Orthopedics, and ${ }^{3}$ Occupational Therapy, Alfred I. duPont Hospital for Children, \\ Wilmington, DE; ${ }^{4}$ School of Biomedical Engineering, Science and Health Systems, Drexel University, Philadelphia, PA; \\ Departments of ${ }^{5}$ Rehabilitation Medicine and ${ }^{6}$ Neurology, Alfred I. duPont Hospital for Children, Wilmington, DE
}

\begin{abstract}
This article presents the state of the art in passive devices for enhancing limb movement in people with neuromuscular disabilities. Both upper- and lower-limb projects and devices are described. Special emphasis is placed on a passive functional upper-limb orthosis called the Wilmington Robotic Exoskeleton (WREX). The development and testing of the WREX with children with limited arm strength are described. The exoskeleton has two links and 4 degrees of freedom. It uses linear elastic elements that balance the effects of gravity in three dimensions. The experiences of five children with arthrogryposis who used the WREX are described.
\end{abstract}

Key words: arthrogryposis, contractures, elbow flexion, exoskeleton, gravity balancing, orthosis, passivity, pediatrics, rehabilitation, robotics.

\section{INTRODUCTION}

People with movement disabilities often rely on assistance from others and/or assistive technology to perform routine functions such as walking or feeding themselves. The primary purpose of assistive technology is for the user to gain independence and self-esteem.

Assistive technologies such as wheelchairs and prosthetic arms have played a large part in the lives of people with disabilities. These technologies range from the highly advanced, such as myoelectric-controlled prosthetic arms or stair-climbing wheelchairs (http://www.independencenow.com/ ibot/index.html), to the simple, such as manual wheelchairs or mechanical hook prehensors. Many factors affect user acceptance of such devices, including cost, simplicity, aes- thetics, maintenance, and ease of control. This article describes a class of devices that assists in upper- and lowerlimb movement by use of passive elements such as springs to counter the effects of gravity. These devices allow users to move their limbs against gravity to ambulate or navigate their hands through space.

A number of disorders affect motor patterns in the limbs, including arthrogryposis multiplex congenita, muscular dystrophy, spinal muscular atrophy, spinal cord injury, cerebral palsy, and stroke. These disorders result in muscular weakness and contractures. People with these disorders significantly depend on their caregivers for personal care.

In arthrogryposis, one or more joints fuse together and, consequently, cannot bend. Contractures and joint weakness are present in the upper and lower limbs. In the upper limbs, triceps function will be present but biceps and brachialis will be nonfunctional or extremely weak. Children with arthrogryposis often do not have enough strength to lift food to their mouths and use awkward compensatory movements or eat with assistance. Arthrogryposis is estimated to occur once in every 3,000 live births [1].

Abbreviations: $3-\mathrm{D}=$ three-dimensional, $\mathrm{BFO}=$ balanced forearm orthosis, WREX = Wilmington Robotic Exoskeleton.

*Address all correspondence to Tariq Rahman, PhD; Department of Biomedical Research, Alfred I. duPont Hospital for Children, 1600 Rockland Road, Wilmington, DE 19899; 302-651-6831; fax: 302-651-6895.

Email: trahman@nemours.org

DOI: 10.1682/JRRD.2005.04.0070 


\section{BACKGROUND}

Early research on orthoses for aiding arm movement was performed at the Case Institute of Technology in the early 1960s [2]. A powered exoskeleton was connected to the floor and controlled by a light source mounted on the wearer's head that activated light sensors in the environment. This device could either be moved directly or preprogrammed to complete different tasks. This research led to the development of the Rancho "golden" arm at Rancho Los Amigos Hospital (now Rancho Los Amigos National Rehabilitation Center) in 1969 [3]. This powered orthosis had seven independent joints and was controlled with tongue switches.

Other orthoses that were developed included Engen's pneumatic orthosis system [4], the Burke orthosis [5], the Musgrave orthosis [6], an exoskeletal mobilizer for amyotrophic lateral sclerosis [7], an intelligent rehabilitative orthotic system [8], an upper-limb motion assist system [9], and a motorized upper-limb orthotic system [10]. These systems were fairly impractical or aesthetically unappealing. None saw commercial success.

The most popular orthosis in use today is the balanced forearm orthosis (BFO) [11], a body-powered device that was developed in the 1950s. The BFO has three joints and allows the user to move only in the horizontal plane. It has a balance point that allows some users to reach their mouths for self-feeding. However, this device does not provide three-dimensional (3-D) movement and is difficult and time-consuming to fit to the user. A vertical-movement version of the device uses elastic bands, but it is only in equilibrium at one vertical level and is seldom used.

Several groups are investigating the use of low-cost passive actuators for enhancing human movement. Cardoso et al. have developed a passive gravity-balanced orthosis for people with neuromuscular arm weakness [12]. Their concept is similar to the Wilmington Robotic Exoskeleton (WREX) in that it uses linear elastic elements. Their device attaches to the side of the wheelchair and does not parallel the human arm. Instead, it attaches to the forearm at a single point. Clinical trials are currently underway.

A group at Rancho Los Amigos National Rehabilitation Center has developed the JAECO/Rancho multilink arm support that is more functional and aesthetically acceptable than the traditional BFO [13]. Its strengths are its modular components, easy set up, and interchangeability between the two arms. A power-assist height-adjustability feature and a powered retractor have recently been added so that patients may recline and maneuver through doorways. This orthosis is currently available through JAECO Orthopedic (Hot Springs, Arkansas).

Hoffman et al. have developed a novel kinematic structure for a passive orthosis that has four degrees of freedom and can be worn by the user [14]. The group intends to power the joints and provide joint coupling that minimizes the power requirements yet still provides adequate function.

Neater Solutions Ltd (Buxton, United Kingdom) has developed an upper-limb orthosis. The configuration is similar to a BFO with an added motorized elevation behind the chair that the user can operate to change the height. This arm was originally developed in the Department of Engineering at Cambridge University. It is commercially available through Neater Solutions Ltd.

Van den Bogert developed the concept of exotendons for assistance with human locomotion [15]. He proposed polyarticular mechanisms based on long elastic cords attached to an exoskeleton and guided by pulleys placed at the joints. He simulated several models of varying complexity for lower-limb movement.

The current study reports on the WREX, a bodypowered orthosis design that is modular and easily mounted to a wheelchair or back brace and provides 3-D arm movements. The unique feature of the WREX is that it allows full passive range of motion for the arm and a sense of flotation that permits voluntary movement.

This article presents the WREX methodology and its application to children with arthrogryposis who walk independently. We present preliminary results from five subjects. We will present results from subjects in wheelchairs in a future report.

\section{METHODS}

\section{Wilmington Robotic Exoskeleton Description}

The goal of the WREX is provision of a sense of flotation that allows persons with neuromuscular weakness to move their arms. Gravity-balancing of the entire arm for all positions in 3-D space allows the person to move the arm with very little effort. To negate the effects of gravity on the upper limb and achieve balance, the WREX uses springs (or elastic bands) to hold up the arm. Springs are appealing because they use stored energy, whereas counterweights 
add inertia. The result is a more compact device. The torques required at the shoulder and elbow for arm elevation are, however, nonlinear. One can appreciate this nonlinearity by noting that holding one's arm straight up is easier than holding it straight out in front. This nonlinearity can be countered by combining linear springs and a moment arm that varies sinusoidally [16].

Initially, we used a linear motor (Liberating Technologies, Inc, Holliston, Massachusetts) to flex the elbow (Figure 1). The motor was connected between a forearm and upper-arm brace. A simple two-directional switch controlled the motor. This method proved unsuccessful because the child could not move his hand to his mouth. The two main reasons for this were (1) he did not have enough strength in his shoulder to externally rotate it and (2) the more the elbow flexed, the more the artificial elbow joint went out of alignment with the anatomical elbow joint. Additionally, this method was uncomfortable to the child because of excessive forces to his elbow.

We then decided to construct a device that could be mounted on a back brace. This transferred the arm loads to the torso and supported the shoulder as well as the elbow. The drawback was that this design added more parts to the mechanism.

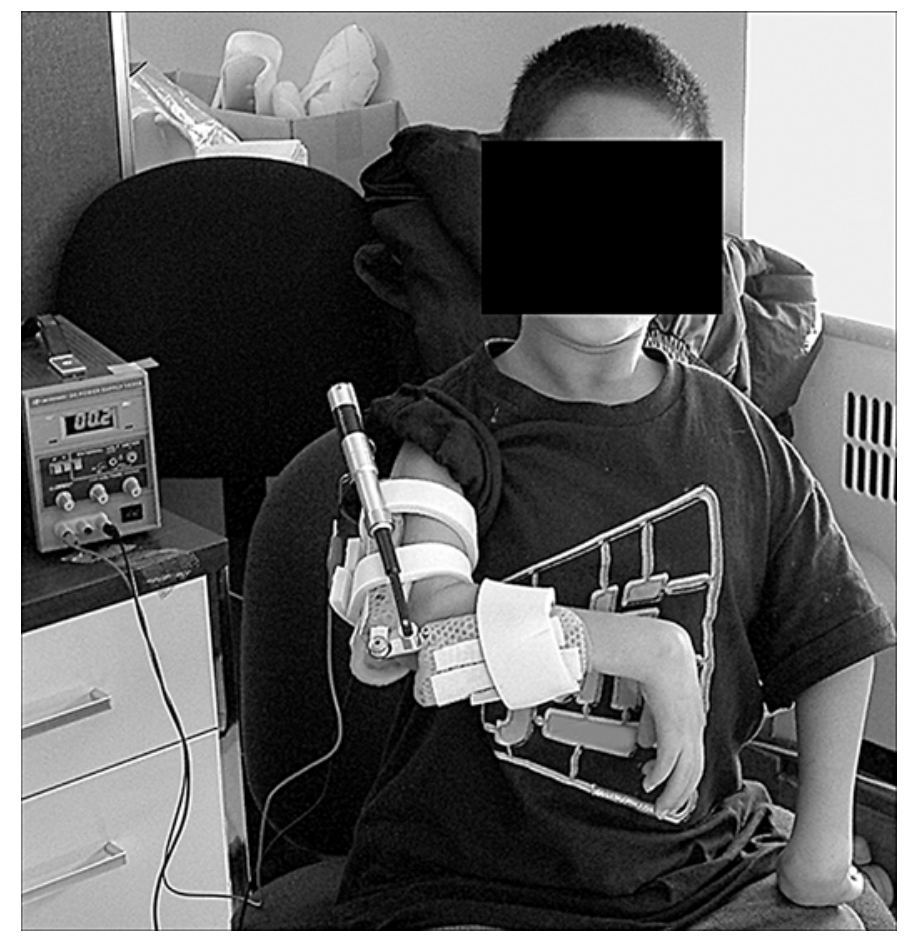

Figure 1.

Subject with elbow flexor mechanism that uses linear motor.
Our goal is to have a perfectly balanced system that freely lowers or raises the arm and then holds it in any position within the workspace. Customized nonlinear coil springs will provide the nonlinear restoring force for balance; however, these springs are difficult to construct or purchase and the result is not sufficiently compact. For the current project, we chose linear elastic elements because they can be stretched over pulleys, require less initial force, their tension can be adjusted easily by changing the number of bands (Sammons Preston Rolyan, Cedarburg, Wisconsin), and they have a smaller profile.

The WREX design evolved over a few years [17] and culminated in the present design (Figure 2). The joint configuration is divided into two rotations at the shoulder and two rotations at the elbow. This allows positioning of the elbow and hand in 3-D space but not pure axial rotation about the humerus or pronation-supination about the elbow. The two perpendicular joints at the shoulder combine for abduction-adduction and flexion-extension (Figure 3). The two elbow joints combine for elbow flexion-extension and compensate for the absence of humeral rotation at the shoulder.

The WREX structure consists of a two-link exoskeleton that shadows the upper arm and forearm. The links are made from steel rods and arranged in the shape of a parallelogram for the upper arm and a single link for the forearm. The parallelogram structure is necessary for the elbow joint to remain vertical as the elbow elevates [16]. This vertical position is necessary for complete gravity compensation for both limbs.

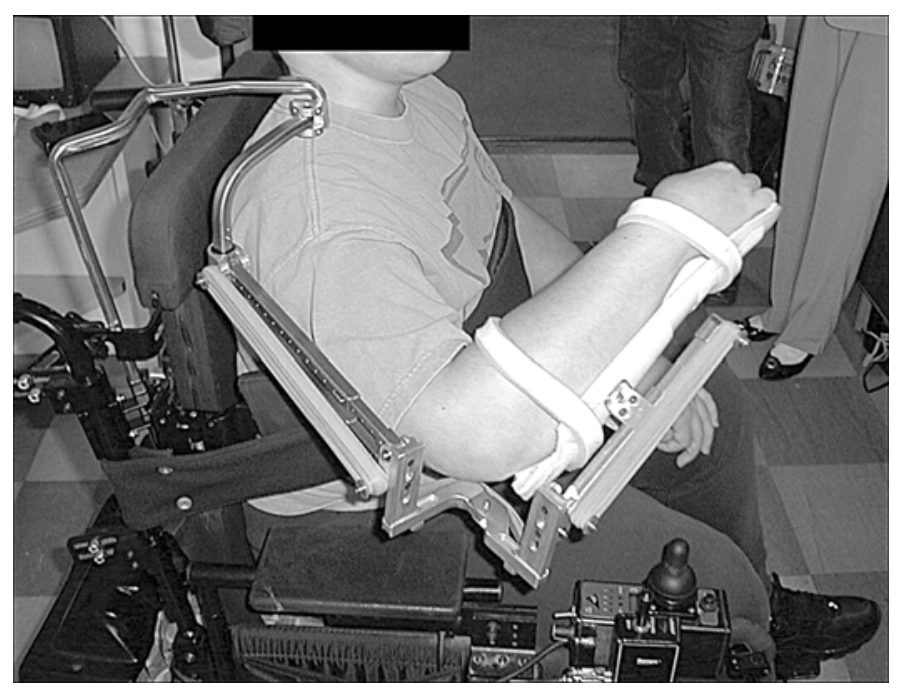

Figure 2.

Wilmington Robotic Exoskeleton attached to subject's wheelchair. 


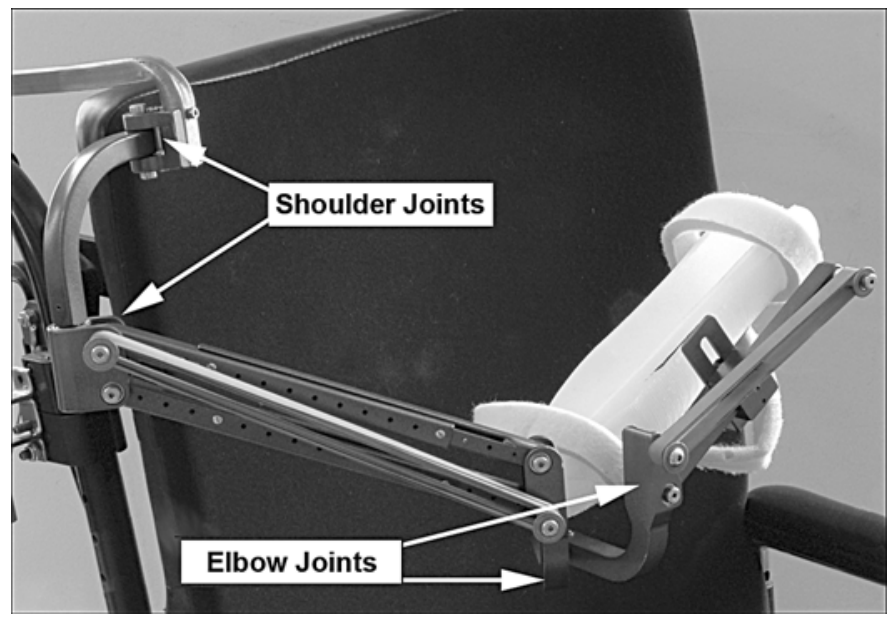

Figure 3.

Joint configuration of Wilmington Robotic Exoskeleton.

A key consideration is configuring the WREX so that the arm is completely balanced, regardless of the position of the hand in 3-D space. As the elbow is flexed or extended, the arm does not deviate from its elevation because the joints of the shoulder and elbow decouple. Each limb has its own antigravity component as a direct result of the parallelogram structure of the upper-arm linkage.

The WREX is currently produced and marketed by JAECO Orthopedic (Hot Springs, Arkansas). The newer version includes a number of adjustments, such as vertical alignment of the base and adjustment of the arm trough along two axes. The arm trough is the standard aluminum trough used for the BFO. This avoids custommolding of braces for each user. The initial model is anodized black.

The entire device is pivoted just above the shoulder. A custom-made arm trough is attached to the forearm link for forearm placement. Adding or subtracting elastic bands accommodates users of different weights. These bands have a consistent elastic behavior, come in different levels of stiffness, and are easily identified by color.

The WREX is mounted on a back brace that allows the user to walk with the system (Figure 4). The WREX was designed to be light and have a small profile for the children in our study. The links have a fixed length, as opposed to the telescoping in the wheelchair version. Through the orthotics clinic at the hospital, a custom back brace is molded for each user. Once a brace is made, it is reinforced with a steel member, which prevents bending

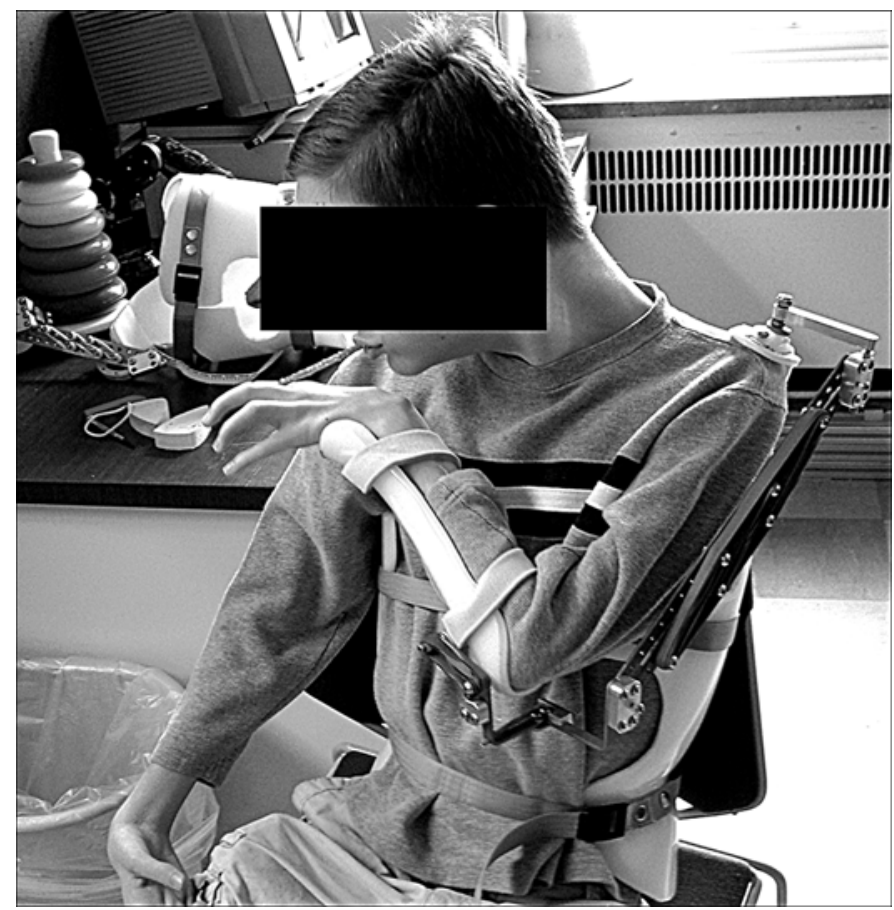

Figure 4.

Subject with arthrogryposis using Wilmington Robotic Exoskeleton for eating. Ulnar deviation makes eating a challenge.

of the brace because of the weight of the WREX and the user's arm. The WREX is sized for each user and the correct number of elastic bands are put in place.

\section{Testing}

Three female and two male subjects with arthrogryposis were fitted with the WREX. Their ages ranged from 6 to 14 years (Table). They were all able to walk independently, although one subject used a walker outside of the home. The occupational therapist and orthopedic surgeon first evaluated these subjects to determine their suitability for the project. The inclusion criteria were weak biceps and inability to lift their hand up to their mouth against gravity. Also required was sufficient prehension and finger dexterity to pick up food. Institutional review board approval was secured, and informed consent was obtained for each subject prior to testing.

The subjects' arm lengths were measured, and a custom WREX was made for each size. A back brace that was similar to a scoliosis brace with a tab over the shoulder was molded for each subject. A steel-reinforcing rod was attached to the back of the brace to support the weight of the WREX and the subject's arm. A post was 
Table.

Characteristics of subjects with arthrogryposis who used Wilmington Robotic Exoskeleton.

\begin{tabular}{clcl}
\hline Subject & Sex & Age at Fitting & Date of Fitting \\
\hline 1 & Female & 6 & February 2004 \\
2 & Female & 6 & January 2005 \\
3 & Male & 14 & October 2004 \\
4 & Male & 10 & March 2005 \\
5 & Female & 9 & June 2005 \\
*Stopped using in June 2005. & & \\
\hline \hline
\end{tabular}

attached to the rod above the shoulder, to which the WREX was mounted. The subject placed his or her arm in a custom-molded trough and Velcro straps secured the arm in the WREX.

Each subject came to the laboratory for fitting, adjusting, and training, which took two to three sessions. Once the subjects were comfortable with the WREX and their caregivers were trained on how to don and doff the WREX, they were asked to take it home and use it indefinitely.

\section{RESULTS}

Four of the five subjects continue to use the WREX at home and in school. Subject 1, a 7-year-old female with arthrogryposis (Figure 5), has been using the WREX for 22 months and relies on it for eating three meals a day. Without WREX, she uses both hands for most foods and leans forward to get the food into her mouth. Her mother assists her in donning and doffing the WREX and is generally very supportive and encouraging. This subject is home-schooled. She came in twice for various adjustments, including changing the lengths of the links as she grew, adjusting the back brace, and changing screws and bushings. A wrist orthotic was made for subject 1 and inserted between the arm trough and her wrist. This helps to elevate her wrist as she scoops food. Subject 1 is unable to pronate or supinate; therefore, getting food into her mouth is a challenge, particularly finger foods. She has to bend her head forward to get these foods into her mouth. The WREX does not have a joint to assist her in pronation. This would be very useful and is currently an area of investigation. Without the WREX, this subject arches her back to elevate her elbow. To minimize this arching with the WREX, we made the back brace longer in the back. This adjustment worked well. Subject 1 also had trouble

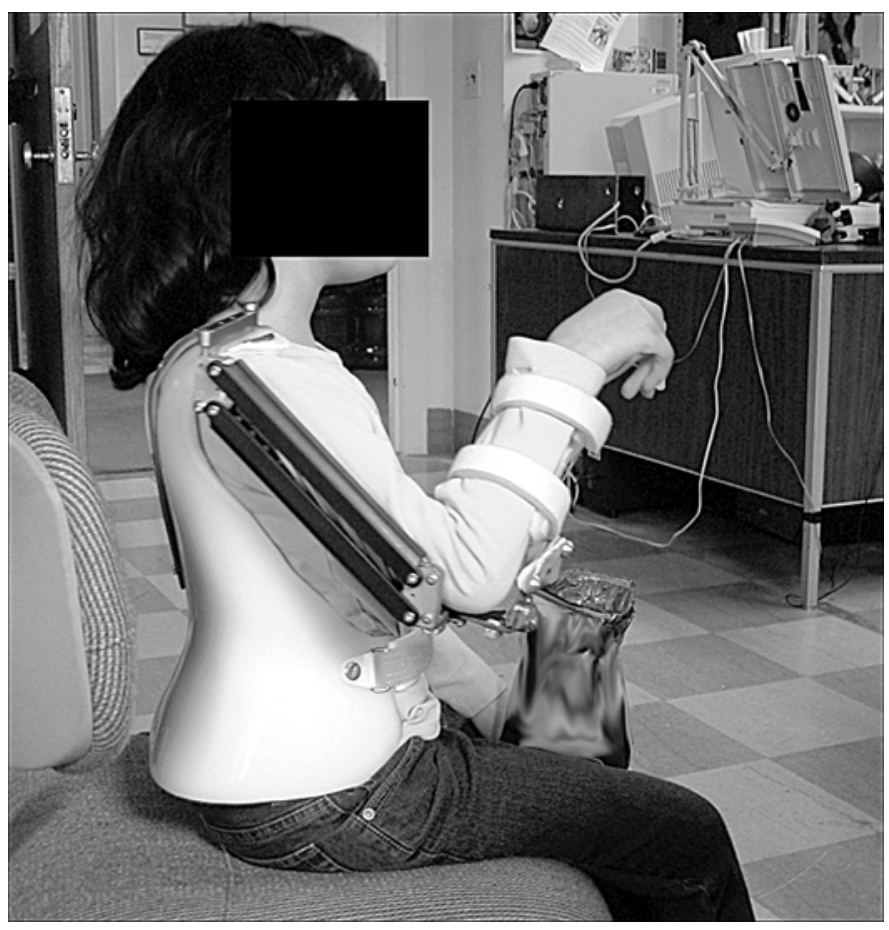

Figure 5.

Subject with Wilmington Robotic Exoskeleton. Cover was placed on upper link as requested by subject.

extending her elbow when it was close to her mouth. This may have been because of slight misalignment of the elbow joint with the WREX. To alleviate this misalignment, we placed a rubber band below the elbow between the elbow joint and the WREX to assist flexing of the elbow joint. This added some resistance when extending the elbow; however, she had enough strength in her triceps to easily overcome this.

Subject 2 is a very active 6-year-old female with arthrogryposis who has had the WREX for almost a year. She has good passive range of motion and can get food to her mouth from a plate. Before receiving the WREX, she used the table to push her hand to her mouth. She uses the WREX daily at home and school, particularly for eating and writing. She has difficulty getting finger foods to her mouth because of an ulnar deviation and profound weakness in elbow flexion. In a follow-up visit, she had difficulty flexing her elbow sufficiently. We placed a rubber band at the elbow joint, similar to subject 1 , which assisted her flexion. She had sufficient strength in her triceps to overcome the added resistance. She has lately reported that she is made fun of in school when she wears the WREX, so she wears it less frequently. 
Subject 3 is a 14-year-old male with arthrogryposis who used the WREX for about 6 months. He is frail and weighs about $80 \mathrm{lb}$. He has considerable ulnar deviation that makes eating foods from his hand very difficult. He combines leaning forward and using the contralateral hand for assistance. He is able to walk on his own most of the time, although he requires assistance getting up from a chair. After adjustments to the WREX were made that allowed him unconstrained movement, he was able to eat food independently; however, reaching up to his mouth was a challenge because of the ulnar deviation. Rubber bands were placed at the elbow joint for assistance in flexion. This helped in eating. His use of the WREX gradually declined and after 6 months he returned it the hospital.

Subject 4 is a 10-year-old male with arthrogryposis who has used the WREX for 9 months. He walks independently; however, he occasionally uses a wheeled walker outside the home. He came with his mother from Wisconsin to take part in the study. The mother was anxious for her son to retain his independence. His bicep strength is trace, he has good triceps strength, and his grasp strength is weak. He uses his last two fingers to pick up food and other items. He has marked ulnar deviation and relies on pronation to eat with his wrist under his chin. After a week of fitting, adjustments, and getting used to the WREX, he was able to eat independently by bringing his hand to his mouth. He was able to use a fork and a spoon; however, his hand was still pronated when it neared his mouth. The WREX allowed him to avoid bending his head down to the table surface. He uses the WREX at home and school and works with the WREX with an occupational therapist.

Subject 5 is a 9-year-old female with arthrogryposis. She weighs $127 \mathrm{lbs}$. She has been wearing the WREX for 5 months. The WREX joints were extended for her because she is heavyset. She also required rubber-band assistance for elbow flexion when her hand was close to her mouth. She uses the WREX at school mainly to raise her hand in class.

\section{DISCUSSION}

The WREX system has been developed for people with muscular weakness in the arms. Its primary function is to act as an assistive orthosis that negates the effects of gravity. We have developed two versions of the WREX: one for people in wheelchairs and one for people who are able to walk independently. The latter was reported in this article, specifically as it concerned children with arthrogryposis.

The WREX's main feature is that it provides 3-D movements in a low-profile exoskeleton structure. This structure allows the WREX to move alongside the arm, thereby minimizing the possibility of the orthosis colliding with obstacles in the immediate environment, such as arm rests, wheelchair backs, and doorways. A few devices, such as overhead slings and the BFO, have been designed for facilitating gravity-assisted movement for people in wheelchairs [11]. However, these devices are seldom used and do not provide sufficient vertical movement. For people who are able to walk, no devices exist that provide 3-D movement of the hand.

This report describes the development of the WREX and a limited study of five children's use. Four of the five subjects continue to use the WREX to varying degrees. One subject relies on it to feed herself everyday. Daily feeding using the WREX requires strong parental commitment, which is present in this child's case, particularly because she is home-schooled. None of the other children are home-schooled, and transporting the WREX between different locations is an issue. It also implies that different people, such as therapists or school nurses, have to put on and remove the devices, which is not always convenient.

Further, one of the subjects reported negative reactions from her peers. This has affected her use, since she does not want to appear more "handicapped.” As a result, she resorts to her old compensatory movements rather than using the WREX in certain settings. Convincing children to use the WREX when they do not see a huge benefit from it is difficult. It comes down to the function/ benefit ratio. For the child who abandoned the WREX after a few months, this ratio was too low for him to continue use. The ulnar deviation was too great for him to get food to his mouth with the WREX. Feeding was the primary function he wished the WREX to support, and if that was still going to be a struggle, he did not see the point of continued use. On the other hand, three of the subjects rely on the WREX for everyday use.

The algorithm for gravity compensation dictates that the pivot post to which the WREX is fixed at the shoulder should always remain vertical [16]. If this constraint is violated, the floating sensation of the arm is compromised and will result in difficulty moving at the extremes of the range. Because children constantly move and lean forward, this constraint is often violated and results in compromised performance. However, one of the subjects has learned to use this extra movement to her advantage by leveraging her torso to move items vertically. 


\section{CONCLUSIONS}

The WREX is a simple, passive device that can potentially maintain the independence and self-esteem of children with neuromuscular difficulties as they perform routine tasks that require manipulation. Although the current study is small, the goal is to expand to a larger population of people with arthrogryposis and other conditions, such as brachial plexus injury and spinal cord injury. The WREX is a potential assistive device and therapy aid for rehabilitating people with conditions such as stroke, spinal cord injury, and cerebral palsy.

\section{ACKNOWLEDGMENTS}

This material was based on work supported by the National Institute on Disability and Rehabilitation Research, grant H133G000117, and Nemours Biomedical Research.

The authors have declared that no competing interests exist.

\section{REFERENCES}

1. Hall JG. Overview of arthrogryposis. In: Staheli LT, Hall JG, Jaffe KM, Paholke DO, editors. Arthrogryposis: A text atlas. Cambridge (England): Cambridge University Press; 1998. p. 1-26.

2. LeBlanc M, Leifer L. Environmental control and robotic manipulation aids. Eng Med Biol Mag. 1982;1(4):16-22.

3. Allen JR, Karchak A Jr, Bontrager EL. Final project report: Design and fabricate a pair of Rancho anthropomorphic manipulator. Downey (CA): The Rancho Los Amigos Hospital, Inc; 1972.

4. Engen TJ. Recent advances in upper-extremity orthotics. In: Murdoch G, editor. The advance in orthotics. London (England): Edward Arnold Publishers Ltd; 1976. p. 117-28.

5. Stern PH, Lauko T. Modular designed, wheelchair-based orthotic system for upper extremities. Paraplegia. 1975; 12(4):299-304. [PMID: 1121416$]$

6. James WV, Orr JF. Upper limb weakness in children with Duchenne muscular dystrophy-A neglected problem. Prosthet Orthot Int. 1984;8(2):111-13. [PMID: 6483591]
7. Sauter WF, Bush G, Sommerville J. A single case study: Myoelectrically controlled exoskeletal mobilizer for amyotrophic lateral sclerosis (ALS) patients. Prosthet Orthot Int. 1989;13(3):145-48. [PMID: 2608422]

8. Lee SH, Agah A, Bekey G. IROS: An intelligent rehabilitative orthotic system for cerebrovascular accident. In: Proceedings of the IEEE International Conference on Systems, Man and Cybernetics; 1990 Nov 4-7; Los Angeles, CA. New York: IEEE; 1990. p. 815-19.

9. Homma K, Arai T. Design of an upper limb motion assist system with parallel mechanism. In: Proceedings of the 1995 IEEE International Conference on Robotics and Automation, Vol. 2; 1995 May 21-27; Nagoya, Japan. New York: IEEE; 1995. p. 1302-7.

10. Johnson GR, Buckley MA. Development of a new motorized upper limb orthotic system (MULOS). In: RESNA 1997 Conference Proceedings; 1997 Jun 20-24; Pittsburgh, PA. Washington (DC): RESNA; 1997. p. 339-401.

11. Chyatte SB, Long C 2nd, Vignos PJ Jr. The balanced forearm orthosis in muscular dystrophy. Arch Phys Med Rehabil. 1965;46(9):633-36. [PMID: 5828903]

12. Cardoso LF, Tomazio S, Herder JL. Conceptual design of a passive arm orthosis. In: Proceedings of the ASME 2002 Design Engineering Technical Conferences and Computers and Information in Engineering Conference; 2002 Sep 29Oct 2; Montreal, Canada. New York: ASME International; 2002. p. 1-13.

13. Leung P. Advances in the Rancho-JAECO multi-link mobile arm support and its application to the spinal injury populations. In: Proceedings of the ACPOC Annual Meeting; 2005 Mar 16-19; Orlando, FL.

14. Hoffman AH, Ault HK, Toriumi H, Smith SA, Felice C. The design and kinematic evaluation of a passive wearable upper extremity orthosis. In: Proceedings of the 2002 Annual RESNA Conference; 2002 Jun 27-Jul 1; Minneapolis, MN. Washington (DC): RESNA; 2002. p. 160-62.

15. Van den Bogert AJ. Exotendons for assistance of human locomotion. Biomed Eng Online. 2003;2:17. [PMID: 14613503]

16. Rahman T, Ramanathan R, Seliktar R, Harwin W. A simple technique to passively gravity-balance articulated mechanisms. ASME Trans Mech Des. 1995;117(4):655-58.

17. Rahman T, Sample W, Seliktar R, Alexander M, Scavina M. A body-powered functional upper limb orthosis. J Rehabil Res Dev. 2000;37(6):675-80. [PMID: 11321003]

Submitted for publication April 19, 2005. Accepted in revised form March 6, 2006. 